Ekuitas: Jurnal Pendidikan Ekonomi

Volume 9, Number 1, Tahun 2021, pp. 79-84

P-ISSN : 2354-6107 E-ISSN : 2549-2292

DOI : $10.23887 /$ ekuitas.v9i1.27123

Open Access: https://ejournal.undiksha.ac.id/index.php/EKU

\title{
Pengelolaan Zakat, Infak, dan Shadaqah oleh Lembaga Amil Zakat, Infak, dan Shadaqah Muhammadiyah (LAZISMU) Buleleng
}

\author{
Riska Yuliana ${ }^{*}$, Naswan Suharsono ${ }^{2}$ \\ 1,2 Universitas Pendidikan Ganesha, Singaraja - Indonesia
}

\section{A R T I C LE I N F O}

Article history:

Received July, 202020

Received in revised form June, 152021

Accepted June, 152021

Available online June, 28 2021

Kata Kunci:

Mencirikan konsep/

variable penelitian, ditulis

dalam tiga sampai enam

kata

Keywords:

It reflects concept/variables

of the study written in

between three up to six

words

\begin{abstract}
A B S T R A K
Penelitian ini bertujuan untuk mengetahui bagaimana pengelolaan zakat, infak dan shadaqah oleh Lembaga Amil Zakat, Infak dan Shadaqah Muhammadiyah (LAZISMU) Buleleng. penelitian ini merupakan penelitian deskriptif. Metode pengumpulan data yang digunakan yaitu wawancara, observasi dan dokumentasi. Sedangkan teknik analisis data yang digunakan yaitu Data Reduction, Data Display dan Conclution Drawing dan Verification. Hasil penelitian ini menunjukkan bahwa dalam pengelolaan zakat, infak dan shadaqah oleh Lembaga Amil Zakat, Infak dan Shadaqah Muhammadiyah (LAZISMU) Buleleng sudah menerapkan fungsi-fungsi manajemen yaitu perencanaan (Planning) dilakukan dengan menentukan tujuan, program dan strategi dalam pengumpulan ZIS, pengorganisasian (Organizing) dilakukan dengan menentukan struktur organisasi, pelaksanaan (Actuating) dilakukan dengan memberikan motivasi dan pengawasan (Controlling) dilakukan dengan membandingkan hasil dengan standar yang dibuat.
\end{abstract}

\section{A B S T R A C T}

This research aims is to find out how the management of zakat, infaq and shadaqah by Lembaga Amil Zakat, Infaq and Shadaqah Muhammadiyah Institutions (LAZISMU) Buleleng. This research is descriptive research. The method use in data collection is interviews, observation and documentation. Meanwhile, the data analysis technique used is data reduction, data display and conclution drawing and verification. The result of this research show and indicate that in the management of zakat, infaq and shadaqah by Lembaga Amil Zakat, Infaq and Shadaqah Muhammadiyah Institutions (LAZISMU) Buleleng has implemented the function of management, there are (planning) is implemented with determine the purposes, programs, and strategies in collecting ZIS, then (organizing) is implemented by determining the organizational structure, (actuating) is implemented with giving comparing between the result and the standart that have been made.

\footnotetext{
* Corresponding author.

E-mail : riskayuliana12081995@gmail.com (Riska Yuliana)
} 


\section{Pendahuluan}

Zakat, infak dan shadaqah (ZIS) merupakan kewajiban bagi umat islam yang mampu, sesuai dengan syariat islam guna dan diberikan kepada yang berhak menerimanya. Seperti yang diungkapkan oleh Soemitra (2009:403) "Zakat berarti kewajiban seorang (muslim) untuk mengeluarkan nilai bersih dari kekayaannya yang tidak melebihi nisab, diberikan kepada mustahik dengan beberapa syarat yang telah ditentukan". Tujuan utama ditunaikannya ZIS adalah untuk meningkatkan keadilan dan kesejahteraan masyarakat. untuk mencapai tujuan tersebut dalam rangka meningkatkan daya guna dan hasil guna, ZIS harus dikelola secara maksimal dengan pengelolaan yang baik sesuai dengan syariat islam.

Pengelolaan sesuai dengan syariat islam yaitu pengelolaan ZIS harus dikelola sesuai hukum islam. Pengelolaan zakat dalam konsep islam diserahkan kepada waliyul amr yang dalam konteks ini adalah pemerintah, dan pemerintah yang mempunyai kewenangan untuk melakukan pengambilan zakat (Triantini, 2010). Mustafa Edwin Nasution (2006) juga mengungkapkan dalam bidang pengelolaan zakat Nabi Muhammad saw, memberikan contoh dan petunjuk operasional. Pengelolaan yang operasional dapat dilihat pada pembagian struktur amil zakat, yang terdiri dari (1) petugas yang mencatat para wajib zakat, (2) petugas yang menaksir, menghitung zakat, (3) petugas yang menarik, mengambil zakat dari para muzakki, (4) petugas yang menghimpun dan memelihara harta, dan (5) petugas yang menyalurkan zakat pada mustahiq (orang yang berhak menerima zakat).

Pengelolaan zakat terus berkembang seiring dengan kondisi politik dan ekonomi Indonesia. Pengelolaan zakat di Indonesia sudah memasuki dimensi baru dalam pengaturannya, yaitu Undang-undang No 38 Tahun 1999 yang dicabut dan kemudian diganti oleh Undang-undang baru yaitu Undang-undang No 23 Tahun 2011 Tentang Pengelolaan Zakat, yang di dalamnya mengatur segala kegiatan yang berhubungan dengan perencanaan, pengorganisasian, pelaksanaan dan pengawasan terhadap pengumpulan, pendistribusian dan pendayagunaan dana ZIS. Dalam pengelolaan sesuai dengan Undang-undang No 23 Tahun 2011 Tentang Pengelolaan Zakat, pemerintah telah mengatur lembaga yang bergerak dalam pengelolaan zakat, yakni Badan Amil Zakat (BAZ) yang berada di bawah nauangan pemerintah dan Lembaga Amil Zakat (LAZ) dengan mendapat legislasi dari Menteri Agama.

LAZ menurut UU No 23 Tahun 2011 Tentang Pengelolaan Zakat adalah lembaga pengelola zakat yang sepenuhnya dibentuk atas prakarsa masyarakat. BAZ dan LAZ masing-masing berdiri sendiri dalam pengelolaan ZIS. Tujuan utama dibentuknya lembaga pengelola zakat (BAZ dan LAZ) yaitu: (1) untuk meningkatkan kesadaran masyarakat, (2) untuk meningkatkan fungsi dan pranan pranata keagamaan dalam upaya mewujudkan kesejahteraan masyarakat, (3) untuk meningkatkan hasil dan daya guna zakat.

Dengan diberlakukannya Undang-undang No 23 Tahun 2011 Tentang Pengelolaan Zakat, mendorong munculnya lembaga-lembaga pengelola zakat di Indonesia. Sejauh ini keberadaan LAZ sudah tersebar di seluruh daerah Indonesia. Hal ini memungkinkan masyarakat memiliki banyak pilihan untuk menyalurkan zakat pada LAZ yang dipercaya memiliki kemampuan dan kapasitas dalam mengelola zakat. Karena tingkat kepercayaan masyarakat didasarkan pada kualitas jasa yang diberikan oleh LAZ tersebut.

Dari uraian di atas dapat di ambil contoh yaitu, Lembaga Amil Zakat, Infak dan Shadaqah Muhammadiyah (LAZISMU) Kabupaten Buleleng merupakan lembaga zakat yang berkhidmat dalam pemberdayaan masyarakat melalui pendayagunaan dan ZIS serta dana sosial keagamaan lainnya. LAZISMU beralamat di Jalan Camar No.8, Kaliuntu. Disamping itu, LAZISMU mempunyai Visi yaitu terciptanya korporasi zakat yang kuat dan terpercaya dan mempunyai Misi yaitu: (1) konsilidasi kelembagaan, (2) standarisasi pengelolaan (manajemen kelembagaan dan SDM) dan (3) berorientasi kepercayaan. LAZISMU melakukan kegiatan perencanaan, pelaksanaan, dan pengkoordinasian dalam pengumpulan, pendistribusian, dan pendayagunaan ZIS serta dana sosial keagamaan lainnya di wilayah Kabupaten Buleleng.

Dengan perkembangan pengelolaan lembaga zakat diharapkan potensi zakat tergali dengan baik. Akan tetapi hal tersebut tidak sesuai dengan yang diharapkan sebagaimana pemaparan Bendahara LAZISMU, bahwa penerimaan dana ZIS yang diterima oleh LAZISMU Buleleng belum optimal, karena masih banyak potensi ZIS yang belum tergarap dengan baik. Walaupun keberhasilan pengelolaan ZIS tidak hanya dilihat dari banyaknya dana ZIS yang terkumpul tetapi juga pada dampak dari pendistribusian dan pendayagunaan ZIS tersebut dapat mewujudkan kesejahteraan dan keadilan sosial dalam masyarakat.

\section{Metode}

Penelitian ini menggunakan metode penelitian deskriftif. Menurut Nasir (2002:61) "Metode deskriftif adalah suatu metode dalam penelitian status sekelompok manusia, suatu objek, suatu set kondisi suatu sistem pemikiran, ataupun suatu kelas peristiwa pada masa sekarang. Tujuan dari penelitian 
deskriptif adalah untuk membuat deskripsi, gambaran atau lukisan secara sistematis, faktual dan akurat mengenai fakta-fakta, sifat-sifat serta hubungan antar fenomena yang diselidiki. Adapun indikator dalam penelitian ini adalah perencanaan, pengorganisasian, pelaksanaan dan pengawasan. Pada penelitian ini akan menggambarkan pelaksanaan pengelolaan zakat, infak dan shadaqah oleh Lembaga Amil Zakat, Infak dan Shadaqah Mauhammadiyah (LAZISMU) Kabupten Buleleng.

Subjek dalam penelitian adalah orang atau badan sebagai sumber data penelitian, yaitu Lembaga Amil Zakat, Infak dan Shadaqah Mauhammadiyah (LAZISMU) Kabupaten Buleleng. Sedangkan informan penelitian ini adalah pengurus LAZISMU yang berjumlah 4 orang.

Sumber data yang digunakan pada penelitian ini yaitu: 1) Data primer, data yang diperoleh secara langsung dari penggurus Lembaga Amil Zakat, Infak dan Shadaqah Mauhammadiyah (LAZISMU) melalui wawancara mengenai pengelolaan zakat, infak dan shadaqah yeng terkait dengan perencanaan, pengorganisasian, pelaksanaan dan pengawasan. 2) Data sekunder, data yang diperoleh dari dokumentasi mengenai pengelolaan zakat, infak dan shadaqah oleh Lembaga Amil Zakat, Infak dan Shadaqah Muhammadiyah (LAZISMU) Kabupaten Buleleng.

Metode pengumpulan data yang digunakan yaitu: 1) Wawancara adalah tanya jawab lisan antara dua orang atau lebih, yaitu pewawancara (interviewer) yang mengajukan pertanyaan dan terwawancara (interviewee) yang memberikan jawaban atas pertanyaan secara langsung (Usman dan Akbar, 1996). Dalam wawancara ini memperoleh keterangan mengenai pengelolaan zakat, infak dan shadaqah yang berkaitan dengan perencanaan, pengorganisasian, pelaksanaan dan pengawasan. Jenis wawancara yang digunakan adalah wawancara terstruktur. 2) Observasi adalah pengamatan dan pencatatan yang sistematis terhadap gejala-gejala yang diteliti (Usman dan Akbar, 1996). Dalam observasi ini peneliti sudah mempersiapkan secara sistematis tentang apa yang akan diobservasi. 3) Dokumentasi yang dikumpulkan merupakan data sekunder, seperti arsip maupun laporan tahunan pengelolaan ZIS.

Teknik analisis data yang digunakan yaitu: 1) Data Reduction (Reduksi Data), pengumpulan data dilakukan dengan observasi, wawancara dan dokumentasi mengenai pengelolaan zakat, infak dan shadaqah oleh LAZISMU. Data yang diperoleh tersebut jumlahnya cukup banyak, sehingga perlu dilakukan reduksi data. Reduksi data adalah merangkum, Memilih hal-hal yang pokok, memfokuskan pada hal-hal yang penting, dicari tema dan polanya dan membuang yang tidak perlu. Dengan demikian data yang telah direduksi dapat memberikan gambaran yang jelas dan mempermudah peneliti untuk melakukan pengumpulan data selanjutnya dan mencari bila diperlukan. 2) Data Display (Penyajian Data), Setelah data direduksi, maka langkah selanjutnya adalah mendisplaykan data atau menyajikan data. Melalui penyajian data tersebut, maka data terorganisasikan, tersusun dalam pola hubungan, sehingga akan semakin mudah dipahami dan merencanakan kerja selanjutnya berdasarkan apa yang telah dipahami tersebut. Dalam penelitian kualitatif, penyajian data bisa dilakukan dengan menggunakan bentuk teks yang bersifat naratif. 3) Conclusion Drawing (Kesimpulan) dan Verification (Verifikasi), Kesimpulan awal yang dikemukakan masih bersifat sementara dan akan berubah bila tidak ditemukan bukti-bukti yang kuat yang mendukung pada tahap pengumpulan data berikutnya. Jika kesimpulan pada tahap awal didukung oleh bukti-bukti yang valid, maka kesimpulan tersebut merupakan kesimpulan yang kredibel.

\section{Hasil dan pembahasan Hasil Penelitian}

Perencanaan zakat, infak dan shadaqah oleh Lembaga Amil Zakat, Infak dan Shadaqah Muhammadiyah (LAZISMU) Buleleng merupakan suatu proses menentukan tujaun, program, strategi dan kebijakan dalam pengumpulan, pendistribusian dan pendayagunaan untuk mencapai tujuan organisasi yaitu mensejahterakan masyarakat. LAZISMU Buleleng melakukan perencanaan dengan menentukan tujuannya yaitu menjadi lembaga amil zakat yang terpercaya, optimalisasi pengelolaan ZIS yang amanah, profesional, dan transparan, optimalisasi pendayagunaan ZIS yang kreatif, inovatif dan produktif, dan optimalisasi pelayanan donator. LAZISMU Buleleng membuat program yang digunakan sebagai pedoman dalam mencapai tujuan. Berdasarkan hasil wawancara dengan pengurus LAZISMU Buleleng terkait hal ini: "LAZISMU Buleleng memiliki program utama ada 4, yaitu program beasiswa kurang mampu, program pembangunan masjid dan sekolah, program tabungan qurban, dan program penanggalangan bencana alam".

Berdasarkan wawancara di atas program LAZISMU Buleleng akan terus dikembangkan dengan harapan mampu meningkatkan kesejahteraan masyarakat. program tersebut harus diimbangi dengan strategi agar dapat berjalan dengan maksimal, sehingga LAZISMU Buleleng memiliki strategi dalam pengumpulan, pendistribusian serta pendayagunaan ZIS. Berdasarkan hasil wawancara dengan pengurus LAZISMU Buleleng terkait hal ini: "Strategi yang kami gunakan dalam pengumpulan zakat yaitu kami 
menyediakan layanan jemput zakat bagi muzakki/donatur yang berhalangan untuk dating langsung ke kantor LAZISMU untuk membayar zakat. Kemudin kami menyediakan celengan infak yang diletakkan di masjid, serta mengoptimalkan pelayanan terhadap muzakki/donator sedangkan strategi pendistribusian agar tersalurkan kepada sasaran yang tepat yaitu kami mendata para mustahik yang berhak menerima zakat, maupun infak dan shadaqah".

Pengorganisasian merupakan proses penyusunan struktur organisasi yang sesuai dengan tujuan organisasi, sumber daya yang dimiliki dan lingkungan. Struktur organisasi adalah sebuah susunan berbagai unit kerja, dan dengan adanya struktur organisasi dapat menggambarkan pembagian kerja, pengelompokkan pekerjaan, relasi antar bagian dan memudahkan untuk koordinasi atau berkomunikasi. Struktur organisasi LAZISMU Buleleng terdiri dari dewan pengawas, dewan syariah, dan dewan pengurus serta 3 bidang yang mengelola ZIS. Berdasarkan hasil wawancara dengan pengurus LAZISMU Buleleng terkait hal ini: "Struktur organisasi LAZISMU Buleleng terdiri dari ketua, wakil ketua, sekretaris dan tiga wakil sekretaris yang membidangi masing-masing bidang. Wakil sekretaris satu membidangi kelembagaan dan litbang yang bertugas untuk melakukan pelatihan dan pembinaan muzakki, mustahik maupun amil sehingga ada pemahaman dan rasa kepercayaan untuk menyalurkan zakat. Wakil sekretaris dua membidangi keuangan dan fundraising, bagaimana pengumpulan dana, menghimpun muzakki dan menjaga loyalitas muzakki. Wakil sekretaris tiga membidangi kerjasama dan program, jadi apa yang akan dijalankan oleh LAZISMU Buleleng atau program-program dibuat oleh bidang ini".

Berdasarkan hasil wawancara tersebut, bahwa struktur organisasi LAZISMU Buleleng sebagaimana yang kutif dari Surat Keputusan Pimpinan Daerah Muhammadiyah, sebagai berikut: Dewan Syari'ah, Ketua: Drs. H. Hidayat Abas Anggota: 1. H. M. Jaiz Jamil, MA 2.Insan Kamil, HR, Badan Pengawas, Ketua : H. Imam Syafi'i, MHI Anggota : 1. H. Sutrisno 2. Drs. H. Amoeng A. Rahman, Badan Pengurus, Ketua : Ja'far Sumarlin, S.PI, Wakil Ketua : Ferry Sarjono, ST, Sekretaris: Syarif Hidayat, Wakil Sekretaris (Kelembagaan, Litbang): Bakhtiar, S.Sy, Wakil Sekretaris (Keuangan, Fundraising): Us Husaini, Wakil Sekretaris (Kerjasama, Program): Hari Prayitno, Anggota Fundraising dan Kerjasama: Bahrudin Basnan, Keuangan dan Kelembagaan: Akhmad Koramil, Program dan Litbang : Teguh Saputra

Pengorganisasian ZIS oleh LAZISMU Buleleng baik pertanggung jawaban sudah sesuai dengan struktur organisasi karena sudah ditetapkan sebelumnya oleh organisasi, dan pembagian kerja sudah sesuai karena masing-masing bidang sudah memiliki tugasnya. Berdasarkan hasil wawancara dengan pengurus LAZISMU Buleleng terkait hal ini: "Pembagian kerja sudah ditetapkan, ada yang mencari donator, ada yang bertugas mengumpulkan dana serta ada yang bertugas mendata. Hal ini sudah tertera pada struktur organisasi".

Pelaksanaan pengelolaan ZIS merupakan tindak lanjut dari perencanaan dan pengorganisasian. Dalam pelaksanaan pengelolaan ZIS yang meliputi pengumpulan, pendistribusian serta pendayagunaan, pengurus terjun langsung untuk menjemput zakat serta mendata para muzakki dan mustahik. Pelaksanaan tersebut tidak terlepas dari adanya motivasi dan komunikasi untuk meningkatkan kinerja, sehingga mendapatkan hasil yang maksimal. Berdasarkan hasil wawancara dengan pengurus LAZISMU Buleleng terkait hal ini: "untuk komunikasi anatar pengurus berjalan dengan baik dan setiap minggu kami mengadakan pertemuan untuk membahas kelanjutan program, mengevaluasi, dan merencanakan apa yang harus dilakukan ke depan. Kemudian Untuk motivasi atau dorongan itu diberikan oleh pimpinan, motivasi diberikan bagaimana memahamkan bahwasanya pengurus di LAZISMU Buleleng apa yang dilakukan untuk kebermanfaatan umat. Jadi motivasi diberikan dengan menanamkan bahwa apa yang dilakukan untuk kebermanfaatan serta menyambung silaturrahmi itu yang diutamakan".

Berdasarkan hsil wawancara tersebut bahwa motivasi diberikan tentunya untuk mengharapkan prilaku yang baik terhadap pengurus sehingga akan menghasilkan kinerja yang baik. Demikian juga dengan komunikasi yang baik akan meningkatkan keefektifan dalam bekerja.

Pengawasan merupakan salah satu cara untuk mengetahui apakah tujuan sudah tercapai. Pengawasan bertujuan untuk memastikan apa yang sudah direncanakan berjalan sebagaimana mestinya ataukah tidak. LAZISMU Buleleng melakukan pengawasan dengan memberikan penilaian terhadap kegiatan yang dilakukan. Berdasarkan hasil wawancara dengan penggurus LAZISMU Buleleng terkait hal ini: "Cara memberiakn penilaian yaitu dengan mengukur program yang sudah berjalan dengan hasil yang sudah dicapai apakah sudah optimal atau belum. Penilaian dilakukan pada saat rapat evaluasi entah itu penilaiannya dalam bentuk angka atau kata mislanya baik atau tidak baik".

Pengawsan dilakukan sesuai dengan standar yang sudah ditetapkan sebelumnya. LAZISMU Buleleng melakukan pengawasan sesuai dengan standar yang dibuat yaitu AD/ART serta program yang sudah ditetapkan. Berdsarkan hasil wawancara dengan pengurus LAZISMU Buleleng terkait hal ini: "standar dan metode penilaian kinerja yang kami gunakan yaitu AD/ART dan program-program kerja yang telah disusun pada saat perencanaa. Sedangkan untuk penilaian kinerja dapat dilihat dari hasil program yang dicapai dengan membandingkan hasil yang diproleh dengan rencana. Kemudian untuk pengambilan tindakan 
koreksi, biasanya penggurus LAZISMU Buleleng mengadakan pertemuan untuk mendapatkan solusi dari masalah tersebut".

Selain itu juga LAZISMU Buleleng melakukan pengawasan antar pengurus karena belum ada pengawas dari eksekutif. Jika LAZISMU Buleleng menemukan penyimpangan, maka akan di dilakukan rapat evaluasi untuk menemukan solusi serta berkonsultasi dengan ketua.

\section{Pembahasan}

Berdasarkan hasil dari penelitian pengelolaan zakat, infak dan shadaqah oleh Lembaga Amil Zakat, Infak dan Shadaqah Muhammadiyah (LAZISMU) Kabupaten Buleleng berdasarkan fungsi-fungsi manajemen yaitu perencanaan, pengorganisasian, pelaksanaan dan pengawasan.

Perencanaan merupakan pedoman atau petunjuk-petunjuk yang harus dituruti jika menginginkan hasil yang baik sebagaimana yang direncanakan. Peran perencanaan dalam bidang manajemen sangat penting karena perencanaan menjadi penentu keberhasilan kegiatan yang akan dikerjakan. Perencanaan ZIS oleh LAZISMU Buleleng dilakukan dengan menentukan tujuan, program dan strategi dalam melakukan perencanaan. Hal ini dibuktikan dengan adanya visi dan misi yang dibuat, strategi-strategi dalam pengumpulan ZIS serta program-program yang direncanakan yaitu program pembangunan masjid dan sekolah, beasiswa kurang mampu, tabungan qurba dan penanggulangan dana untuk bencana. Sesuai dengan teori yang dikemukakan oleh Hasibuan (2014) menyatakan bahwa perencanaan yang baik mengandung unsur-unsur yang meliputi tujuan, kebijaksanaan, prosedur, rule, program, anggaran, metode, dan strategi.

Pengelolaan zakat, infak dan shadaqah oleh LAZISMU Buleleng sudah menerapkan fungsi pengorganisasian. Hal ini dibuktikan dengan adanya struktur organisasi LAZISMU Buleleng yang dibentuk dan disahkan oleh Piminan Daerah Muhammadiyah Kabupaten Buleleng. Struktur organisasi tersebut menggambarkan bahwa adanya pertanggung jawaban yang sesuai dengan kewenangan. Namun pembagian kerja atau deskripsi pekerjaan belum terperinci dan jelas disetiap divisinya. Sehingga perlu dibuatkan deskripsi pekerjaan, dan tidak akan terjadi tumpang tindih tugas dan pekerjaan. Dengan begitu akan mempermudah untuk dikoordinasi dan mempermudah untuk melakukan evaluasi kinerja. Sesuai dengan yang diungkapkan oleh Stoner, Freeman, \& Gilbert, bahwa ada empat pilar yang menjadi dasar proses pengorganisasian yaitu pembagian kerja, pengelompokkan pekerjaan, penentuan relasi antarbagian dalam organisasi dan koordinasi (Sule \&Kurniawan, 2006).

Pelaksanaan merupakan usaha untuk menggerakkan orang-orang, agar bekerja dengan maksimal untuk mencapai tujuan yang telah ditetapkan. Pelaksanaan zakat, infak dan shadaqah oleh LAZISMU Buleleng tidak terlepas dengan adanya motivasi dan komunikasi yang diberikan agar memberikan semangat kepada pengurus dalam menjalankan tugas. Hal ini dibuktikan dengan pengurus datang langsung ke rumah muzakki untuk mengambil zakat atau mendata masyarakat yang benar-benar berhak menerima ZIS. Hal ini sejalan dengan hasil penelitian Nazlah Khairina (2019) bahwa cara penghimpunan dana zakat, infak dan sedekah yang dilakukan oleh Lembaga Amil Zakat Nurul Hayat Cabang Medan yaitu amil datang ke tempat muzakki, muzakki mentransfer dana ke Nurul Hayat dan muzakki datang langsung ke kantor Nurul Hayat. Selain itu juga penggurus melakukan pertemuan setiap minggu untuk melakukan evaluasi dan menindak lanjuti apa yang akan dilakukan untuk ke depannya. Sikap yang dilakukan oleh pengurus memberikan pelayanan yang baik kepada muzakki dan mustahik. Selain itu pengurus juga melakukan kerjasama dengan LAZISMU lain seperti LAZISMU Denpasar, sehingga akan mendorong pengurus dalam berprilaku dan bersikap terhadap kinerja. Sesuai dengan teori Griffin yang menyatakan bahwa kinerja yang baik ditentukan oleh tiga faktor yaitu motivasi, kemampuan dan lingkungan pekerjaan (Sule \&Kurniawan, 2006).

Pengawasan merupakan kegiatan evaluasi terhadap keberhasilan dalam pencapaian tujuan dan target sesuai dengan rencana yang telah dibuat. Pengawasan berkaitan dengan uapaya untuk mengamankan jalannya aktivitas organisasi. Dan mencegah atau memperbaiki kesalahan penyimpangan atau kegiatan yang tidak sesuai dengan perencanaan. Pengawasan ZIS oleh LAZISMU Buleleng dilakukan dengan melakukan penilaian yang sesuai dengan standar yang sudah ditetapkan, serta melakukan tindakan jika ada penyimpangan. Penilaian dilakukan dengan membandingkan hasil yang diperoleh dengan rencana apakah sudah optimal dan sesuai dengan standar yaitu program yang sudah dibuat. Jika pengumpulan belum sesuai dengan standar, maka pengurus akan mengunjungi atau mengingatkan kepada muzakki untuk membayar zakat. Hasibuan (2014) mengungkapkan bahwa pengawasan dilakukan secara bertahap melalui langkah-langkah, yaitu menentukan standar-standar yang akan digunakan dasar pengendalian, mengukur pelaksanaan atau hasil yang telah dicapai, membandingkan pelaksanaan atau hasil dengan standar dan menentukan penyimpangan jika ada serta melakukan tindakan perbaiakan, jiak terdapat penyimpangan agar pelaksanaan dan tujaun sesuai dengan rencana. 


\section{Simpulan dan saran}

\section{Simpulan}

Berdasarkan hasil penelitian dan pembahasan pada bab sebelumnya dapat diambil kesimpulan tentang pengelolaan zakat, infak dan shadaqah oleh Lembaga Amil Zakat Infak dan Shadaqah Muhammadiyah (LAZISMU) Buleleng. Kesimpulan tersebut adalah: Perencanaan zakat, infak dan shadaqah oleh Lembaga Amil Zakat Infak dan Shadaqah Muhammadiyah (LAZISMU) Buleleng dilakukan dengan menentukan tujuan, program dan startegi dalam pengumpulan, pendistribusian dan pendayagunaan ZIS. Pengorganisasian Lembaga Amil Zakat Infak dan Shadaqah Muhammadiyah (LAZISMU) Buleleng dilakukan dengan menentukan struktur organisasi oleh Pimpinan Daerah Muhammadiyah Kabupaten Buleleng yang menggambarkan pembagian kerja serta pertanggung jawaban masing-masing bidang. Pelaksanaan zakat, infak dan shadaqah oleh Lembaga Amil Zakat Infak dan Shadaqah Muhammadiyah (LAZISMU) Buleleng dilakukan dengan memberikan motivasi dan komunikasi yang baik antar pengurus. Pengawasan zakat, infak dan shadaqah oleh Lembaga Amil Zakat Infak dan Shadaqah Muhammadiyah (LAZISMU) Buleleng dilakukan dengan membandingkan hasil yang diperoleh dengan standar yang sudah dibuat.

\section{Saran}

Berdasarkan hasil penelitian yang diperoleh penulis, maka beberapa saran yang dapat penulis berikan sebagai sumbangan terkait penelitian yang dilakukan, yaitu: Bagi Lembaga Amil Zakat, untuk lebih memahami dan menerapkan tentang manajemen yang meliputi perencanaan, pengorganisasian, pelaksanaan dan pengawasan sehingga pengelolaan ZIS dapat berjalan secara efektif dan efisien. Serta memperluas dan memaksimalkan sosialisasi kepada masyarakat dengan memanfaatkan teknologi baik melalui media elektronik maupun media cetak. Bagi Peneliti Selanjutnya, penelitian ini diharapkan dapat membantu untuk melakukan penelitian selanjutnya baik di bidang pengelolaan zakat, infak dan shadaqah maupun di sudut pandang yang berbeda, sehingga dapat memperkaya kajian ekonomi.

\section{Daftar Rujukan}

Nasir, M. (2002). Metode Analisi Deskriptif. Yogyakarta: ANDI

Nasution, M. E. 2006. Pengenalan Eksklusif Ekonomi Islam. Jakarta: Kencana Prenada Media Grup

Soemitra, A. (2009). Bank dan Lembaga Keuangan Syariah. Jakarta: Kencana

Triantini, Z.E. (2010). Perkembangan Pengelolaan Zakat di Indonesia. Al-Ahwal. 3(1):87-100. http://ejournal.uin-suka.ac.id

Undang-undang Nomor 23 Tahun 2011 Tentang Pengelolaan Zakat.

Usman, H \& Purnomo, S. A. (1996). Metodologi Penelitian Sosial. Jakarta: Bumi Aksara

Sule, Erni, T \& Saefullah, K. (2006). Pengantar Manajemen. Jakarata: Kencana

Hasibuan, M,S.P. (2014). Manajemen: Dasar, Pengertian, dan Masalah. Jakarta: Bumi Aksara.

Khairina, N. (2019). Analisis Pengelolaan Zakat, Infak Dan Sedekah (ZIS) Untuk Meningkatkan Ekonomi Duafa (Studi Kasus Di Lembaga Amil Zakat Nurul Hayat Cabang Medan. Jurnal At-Tawassuth. 7(1):160-184. Tersedia dalam http://jurnal.uinsu.ac.id diakses pada 5 September 2019. 